\title{
Maternal Mental Health and Child Adjustment Problems in Response to the COVID-19 Pandemic in Families Experiencing Economic Disadvantage
}

\author{
Stephanie F. Thompson ${ }^{1}$ (1) - Lisa Shimomaeda ${ }^{1} \cdot$ Rebecca Calhoun $^{1} \cdot$ Natasha Moini ${ }^{1} \cdot$ Michele R. Smith $^{1}$. \\ Liliana J. Lengua ${ }^{1}$
}

Accepted: 6 December 2021 / Published online: 18 January 2022

(c) The Author(s), under exclusive licence to Springer Science+Business Media, LLC, part of Springer Nature 2021

\begin{abstract}
Parents living in low-income contexts shouldered disproportionate hardships during the COVID-19 pandemic with consequences to maternal mental health and child adjustment. The current study uses a sample of first-time mothers $(N=147)$ of young toddlers, all living in low-income contexts, to examine the roles of pre-pandemic and COVID-19-specific risk and individual resilience factors in the prediction of changes to maternal mental health coinciding with the onset of the pandemic. Maternal mental health symptoms, in turn, were examined as predictors of child adjustment problems across 6 months of the pandemic and as a potential mechanism conferring pandemic risks to children. While pre-pandemic cumulative contextual risk (i.e., low income, single parent status, adolescent parent status, financial instability) did not predict changes in maternal mental health from prior to during the pandemic, COVID-19-specific health risks predicted changes in maternal mental health from before the pandemic, as well as across 6 months of the pandemic. Regarding individual resilience factors to changes in maternal mental health, pre-pandemic self-compassion predicted better maternal mental health during the pandemic, as did COVID-19-specific appraisal and coping strategies. In turn, maternal mental health predicted children's early pandemic levels of adjustment problems and changes in adjustment problems across 6 months of the pandemic, with maternal mental health serving an indirect pathway of COVID-19-specific health risks to children's adjustment. The findings highlight pathways of risk and resilience during a global health crisis and point to targets for interventions in community level crises to promote maternal and child mental health.
\end{abstract}

Keywords Maternal mental health $\cdot$ Risk $\cdot$ Resilience $\cdot$ Pandemic $\cdot$ Child adjustment

The global COVID-19 pandemic has posed a disproportionate burden on people from economically disadvantaged communities (e.g., Fortuna et al., 2020; Holmes et al., 2020a, b) who are less likely to have buffers to pandemic hardships (Jenkins et al., 2021). This unequal burden of the pandemic, reflective of the structural inequities impacting families living in low-income contexts, are staggering. This is evidenced by increasing symptoms of anxiety and depression in adults, and particularly in parents with young children (Pierce et al., 2020). During the pandemic, families have varied in the degree to which they experienced

Stephanie F. Thompson

sfengler@uw.edu

1 University of Washington, Seattle, WA, USA
COVID-19-specific contextual hardships such as job or income loss and changes in childcare, as well as COVID-19 health risks such as being exposed to or contracting COVID19 (Jenkins et al., 2021). These hardships may have varying effects on parents' and children's mental health. Examination of the unique contributions of pre-existing risk factors as well as COVID-19-specific risk factors to pandemic adjustment is critical to inform models of mental health during community level adversity.

Individual changes in mental health symptoms in the context of community disasters are a function not only of external risks, but also of internal resilience factors (Bonanno et al., 2010; Masten, 2021). As such, examining factors such as self-compassion, appraisal, and coping, which may directly reduce maternal mental health problems in response to adversity, is a research priority for the COVID-19 pandemic (Holmes et al., 2020a, b). 
Further, maternal mental health problems have significant consequences for children's mental health (Stein et al., 2014), and conceptual models linking COVID-19 to child adjustment through caregiver well-being have been articulated (Prime et al., 2020). Few, if any, studies have simultaneously considered the roles of pre-existing risk, COVID-19-specific contextual hardships, and COVID-19 health risks in relation to changes in both maternal and child mental health from prior to during the pandemic, and fewer studies still have tested pathways of risk to children's adjustment during a global health crisis.

The current study examines predictors of changes to maternal mental health from prior to the pandemic into the early pandemic, and in turn, examines whether changes in maternal mental health from April 2020 to October 2020 predict changes in children's adjustment. The study examines these associations in a group of diverse women and children, all living in the context of low income, to both highlight the toll of cumulative hardships facing some American families, and also to highlight potential sources of resilience in a time of global public health crisis.

\section{Maternal Mental Health in the COVID-19 Crisis}

Increased rates of mental health symptoms are often observed in the context of large-scale disasters due to the disruptions and threats to the lives of many (Masten \& Motti, 2020). For example, poorer mental health outcomes were reported among individuals practicing social distancing and quarantining in the 2002 severe acute respiratory syndrome (SARS) and 2012 Middle East respiratory syndrome (MERS) pandemics (Brooks et al., 2020). Early research on parents' mental health response to the COVID-19 pandemic similarly suggests worsening mental health symptoms from prior to the pandemic (Cameron et al., 2020; Gassman-Pines et al., 2020; Patrick et al., 2020), especially among mothers who have experienced financial insecurity (Russell et al., 2020). Most findings about changes in maternal mental health from pre-pandemic to during the pandemic compare mental health symptom levels to typical population norms (Cameron et al., 2020) or have relied on retrospective reporting (Patrick et al, 2020) or single-item measures of mental health (GassmanPines et al., 2020). These methodologies, each with their own limitations, highlight the need for additional, longitudinal research into changes in maternal mental health symptoms that correspond with the start of the pandemic, as well as symptom changes during the course of the pandemic.

\section{Cumulative Contextual Hardship Predicts Adult Mental Health}

The links between economic stress and parental mental health have been long established (Masarik \& Conger,
2017). Broadly, low income is associated with additional markers of adversity, including adverse childhood experiences (ACES), adolescent parenthood, low maternal educational attainment, and general financial insecurity. These risk factors have cumulative effects on adult adjustment (Evans \& Cassells, 2014). Such indicators are also risk factors for job loss and family hardships within the COVID-19 pandemic (Penkler et al., 2020) which have been found, in national surveys, to be among the most stressful COVID-19 stressors (Park et al., 2021). There is a paucity of literature on how pre-existing cumulative risk experiences, in tandem with pandemic risks, predict maternal mental health adaptation to the pandemic. Further, these pre-pandemic contextual hardships appear to elevate the risk for COVID-19-specific health risk exposures, further contributing to poor mental health among parents, with downstream consequences for offspring (Prime et al., 2020).

\section{Pandemic Specific Risk Factors May Predict Increases in Adult Mental Health Problems}

In studies of traumas, disasters, and terrorist events, a dose-response relation of risk to mental health problems is often observed (Masten, 2021). On balance, the higher the frequency, intensity, and severity of exposure to disasterrelated risk factors, the greater the impact on adjustment. This suggests that in order to understand maternal mental health response to the pandemic, it is important to consider the degree of COVID-19-related hardships experienced by the family. The pandemic has imposed both contextual hardships and health-related risk exposures. Contextual hardships include changes in employment, income, childcare, and housing security. In addition, the pandemic presents a health burden through potential exposure to COVID-19 or illness itself. Pakenham and colleagues (2020) considered context variables in the prediction of mental health symptoms among Italian nationals during lockdown, finding that factors such as household density, potential work exposure to the virus, job loss, as well as infection or a family member's infection correlated with symptoms of anxiety and depression. Gassman-Pines et al. (2020) considered the cumulative effect of COVID-19 hardships spanning job loss, income loss, caregiver burden, and household illness and found evidence supporting the cumulative risk approach to modelling risk, wherein each individual hardship predicted maternal mental health and an additive effect was observed.

\section{Individual Resilience Factors May Predict Better Mental Health}

Several individual factors may play a role in promoting better mental health during a major disaster or traumatic event, including self-compassion, appraisal and coping. 
Self-compassion, or mindful understanding of one's pain and recognition of pain as part of a larger human experience, is also thought to alleviate anxiety, depression, and general distress through cognitive and attentional routes (MacBeth \& Gumley, 2012). In the context of disaster, self-compassion may reduce the risk of mental health deterioration (Lea et al., 2020) and recent research suggests the promise of mindfulness-based interventions for promoting post-disaster resilience (Panting et al., 2020). However, there is a paucity of empirical research examining the potential promotive effects of self-compassion to reduce mental health problems during the pandemic.

A crucial component of the impact of a stressful event is an individual's appraisal of the event as exceeding one's resources to manage it or as threatening to their wellbeing (Lazarus \& Folkman, 1984). As such, appraisal may be an important COVID-19 risk and resilience factor. Aligning with cognitive processing models of adjustment, an internalized appraisal of high threat of harm, whereby an individual perceives the world as a dangerous or threatening place, low self-judgement, reflecting a low sense of agency and ability to manage challenges of daily life, and low trustworthiness of others, reflecting a distrust of individuals within interpersonal relationships, is typically associated with increased mental health symptoms, including anxiety and depression (Vogt et al., 2012). High threat appraisal predicts mental health symptoms in the wake of disaster (Piotrkowski \& Brannen, 2002).

Coping efforts are the conscious, volitional efforts to regulate emotion, cognition, behavior, physiology, and the environment in response to stress (Compas et al., 2001) and therefore may influence adjustment to the COVID-19 pandemic. Coping can be differentiated between active or approach and avoidant strategies. Active coping approaches involve thinking about solving the problem or thinking more positively about the problem. Avoidant coping strategies involve trying to stay away from the problem or repressing thoughts about it (Lazarus \& Folkman, 1984). Active coping strategies are related to lower levels of psychological symptoms and avoidant strategies tend to be related to higher levels mental health problems (Compas et al., 2001). However, there is some research suggesting these relations may be dependent on stressors or contexts, specifically that avoidant coping may not be detrimental when managing uncontrollable events, particularly in the short-term (Wadsworth, 2015). Consistent with this finding, both active and avoidant approaches have been negatively associated with depressive symptoms in the context of the COVID-19 pandemic (Park et al., 2021).

\section{Maternal Mental Health is Critical to Child Mental Health}

It is well accepted that maternal mental health predicts children's mental health (Goodman et al., 2011; Stein et al., 2014). Effects of maternal mental health symptoms are evident as early as infancy on outcomes such as behavioral dysregulation, attachment, and cognitive development (Lyons-Ruth et al., 2002; Stein et al., 2014), and may persist through adolescence and into adulthood (Stein et al., 2014). There is some evidence that children whose parents have had a recent episode of depression are at double odds of psychiatric disorder relative to children who have parents without a recent episode, even among children of parents with recurrent depression (Mars et al., 2012). This finding suggests that children's mental health may register changes in parental mental health at a fairly granular level. Prior research has demonstrated that, in the aftermath of disasters, children face worse outcomes when their caregiver's mental health declines as a function of the disaster (Masten \& Narayan, 2012). During the COVID-19 pandemic, caregivers with children under the age of 5 years old are particularly susceptible to heighted levels of distress (Pierce et al., 2020). However, how changes in maternal mental health predict changes in young toddlers' mental health has not been previously studied. Further, exposure to maternal mental health symptoms in the context of additional risks such as low-income (Stein et al., 2008) may be particularly disruptive to children's adjustment. For example, children whose mothers experience similar levels of postnatal depression, but who grow up in higher socioeconomic contexts, are less likely to be adversely affected (Stein et al., 2014). Additionally, maternal mental health partially mediates the effects of income-related risk on children's adjustment (Eamon \& Zuehl, 2001) and may well serve as a pathway of the effects of COVID-specific family stressors (Prime et al., 2020). Together, these findings underscore the importance of maternal mental health symptoms, particularly those co-occurring with additional risks, for children's mental health.

\section{This Study}

This study examined predictors of pre- to during-pandemic changes to maternal mental health symptoms, and whether changes in maternal symptoms during the pandemic account for changes in children's adjustment problems. This study is unique in leveraging longitudinal data collected before the outbreak of COVID-19 as well as data collected across the first 6 months of the pandemic. Study participants were diverse mothers and young toddlers living in the context of low income, who represent individuals experiencing a disproportionate toll of the global health crisis. In line with stated research priorities, this study considers individual risk and resilience factors potentially relevant to maternal mental health adaptation. We predict that pre-existing contextual risk, COVID-19-specific contextual hardships, and COVID19 health risks would predict greater increases in maternal mental health symptoms. Above these risk factors, we predict that preexisting self-compassion and active coping will 
predict smaller increases in maternal mental health symptoms. In contrast, we predict that high threat appraisal and avoidant coping would predict greater increases in symptoms. Finally, we predict that, above the effects of risk, maternal mental health will predict child adjustment problems concurrently and prospectively and mediate the effects of COVID-19 risk on child adjustment.

\section{Methods}

\section{Participants}

Participant were drawn from a sample of first-time mothers who were recruited in their second trimester of pregnancy from local hospitals, public health clinics, and charitable agencies and followed through their infants' early development. Families lived in low-income contexts $(\leq 200 \%$ of the US Federal Poverty Level, operationalized as less than $\$ 45,000$ annual income for a family of three). 163 mothers participated in postpartum assessment completed prior to the outbreak of the pandemic, when their infants were approximately 6 months of age. 147 participants completed the April 2020 pandemic survey, and 152 women completed the October 2020 pandemic survey. Mothers were predominately women of color (33\% African American, 24\% Caucasian, 19\% Multiracial, 13\% Asian, 6\% Hispanic, 4\% Native American, 2.0\% Pacific Islander). Mothers' ages ranged from 18-43 years, $M=26.93$, $S D=6.15$. Mothers' educational distribution was $5 \%$ mothers with $11^{\text {th }}$ grade or less, $33 \%$ with completed high school or GED, 33\% with some college, technical or professional school, $23 \%$ college graduates, and $6 \%$ with post-graduate education. $29 \%$ were single heads of household, $25 \%$ were living with a partner, and 25\% were married (living together), and $21 \%$ other. To participate, mothers were required to have reasonable proficiency in English and be 18-years of age or older. Women who self-reported addiction to alcohol or other substances, reported mental health illnesses which caused altered perceptions of reality, who had previously given birth, or who were pregnant with multiples were ineligible for the study. Child participants included 52\% girls, 33\% multiracial, 28\% African American, 23\% Caucasian, 10\% Asian, 4\% Hispanic, $2 \%$ Native American, and $1 \%$ Pacific Islander. Infants were 2.99 to 7.89 months old at the pre-pandemic assessment $(M=4.88$ months, $S D=0.82)$. In April 2020, which coincided with a local stay-at-home order, children were 7.76 to 37.18 months old $(M=21.35$ months, $S D=8.47)$. In October 2020, the young toddlers were 12.85 to 41.92 months old ( $M=27$ months, $S D=8.55)$.

\section{Procedures}

As part of the longitudinal study, families completed 4 assessments of behavioral, physiological, and questionnaire measures at the University research laboratory. These assessments occurred when mothers were in their second trimester of pregnancy, and when infants were $2-4$ months ( $2^{\text {nd }}$ assessment), 4-6 months ( $3^{\text {rd }}$ assessment), and $10-12$ months old ( $4^{\text {th }}$ assessment). Prior to the first assessment, participants provided written consent to participate in the study and consented to be contacted for follow-up assessments. Participants were compensated $\$ 90$ for participating in the first assessment, and compensation increased by $\$ 10$ at each subsequent assessment. Compensation was given for parking and transportation. The pandemic outbreak began after all participants had completed their $3^{\text {rd }}$ assessment, but before all participants had completed the $4^{\text {th }}$ assessment. As such, measures from the $3^{\text {rd }}$ assessment were used as pre-pandemic measures ("pre-COVID"). To assess participants' experiences and responses to the pandemic, mothers completed online questionnaires administered in April 2020 ("COVID-T1"), one month after stayat-home and social distancing orders were implemented, and again in October 2020 ("COVID-T2"). At COVID-T1, local county positive cases, hospitalizations, and deaths were $0.15,0.03$, and 0.01 percent by population (respectively) relative to national averages of $0.27,0.02$, and 0.02 percent by population (respectively). At COVID-T2 these local rates were $0.26,0.01$, and 0.01 percent by population (respectively) relative to national averages of 0.60 , 0.04 , and 0.01 percent by respectively (CDC, 2020; King County, 2020). Participants were compensated $\$ 25$ for completing each questionnaire. All study procedures were approved by the Human Subjects Institutional Review Board at the University of Washington. The length of time between pre-COVID-19 and the first COVID-19 assessment varied across families $(M=501.18$ days, $S D=268.68$ days, Range $=77-916$ days). However, the length of time between assessments was not correlated with child or maternal mental health $\left(r_{\mathrm{s}}=-0.01\right.$ to -0.10 , all $\left.n s\right)$ and as such was not examined further.

\section{Measures}

The pre-COVID assessment included measures of preCOVID-19 contextual risk, self-compassion, and maternal mental health.

Pre-COVID-19 Contextual Risk A measure of pre-pandemic cumulative contextual risk was assessed and included 5-factors: income, financial insecurity, adolescent parent status, low maternal educational attainment, and adverse childhood experiences (ACEs). Continuous scores (income, financial insecurity) were converted into proportions of the total possible score such that each score ranged from 0 to 1 . This avoided artificially dichotomizing continuous variables (Evans et al., 2013). Dichotomous 
factors were scored as $0=$ not present, $1=$ present. The total cumulative risk score was the sum of all component factors.

Prior to the pandemic, mothers reported on family income from all sources on a 14 -point scale $(1=\$ 14,570$ or less, $2=\$ 14,571-\$ 18,310,3=\$ 18,311-\$ 22,050$, etc.; $M=5.23$, $S D=3.81$ ). Responses were reversed scored and converted to a proportion score for this study. Participants reported on their financial security on seven items assessing the degree to which they had enough money to afford living essentials (e.g., home, food, medical care, etc.) on a 5-point Likert scale $(1=$ strongly disagree to $5=$ strongly agree $)$. Scores were averaged, $M=3.43, S D=0.83$, and reversed so that higher scores represented higher insecurity. Mothers reported on their age at the time of the study child's birth and $10 \%$ were adolescent parents ( $\leq 19$ years). Mothers reported on their educational attainment. Risk was indicated by mothers' not graduating from high school (5\% of the sample). Mothers reported their history of ACEs. Risk was indicated by $1+\operatorname{ACE}$ ( $84 \%$ of the sample).

Self-compassion At the pre-pandemic assessment, individuals reported on the degree to which they adopted a nonjudgmental understanding of pain, the universality of the human experience, and the worthiness of all people - oneself included - of compassion using the Self-Compassion ScaleShort Form (SCS-SF; Raes et al., 2011). Responses were indicated using a 5-point scale ranging from 1 (almost never) to 5 (almost always). Six 2-item factors spanned self-kindness, common humanity, and mindfulness. The SCS-SF has demonstrated adequate validity, consistency with a reliability alpha around 0.85 (e.g., Hayes et al., 2016; Kelly et al., 2013). The alpha for the current study was found to be 0.88 .

Maternal Mental Health Measures of maternal anxiety and depression were obtained at the pre-COVID, COVIDT1, and COVID-T2 assessments. Participants rated their anxiety symptoms using the 7-item Generalized Anxiety Disorder Scale (GAD-7; Spitzer et al., 2006). Participants reported how often they were bothered by each of the 7 core symptoms of generalized anxiety disorder on a 4-point Likert scale $(0=$ not at all to $3=$ nearly every day). The scale has evidenced good reliability and validity in general population studies, with age invariance (Löwe et al., 2008). The alphas for the scale were $0.87,0.95$ and 0.93 respectively for pre-COVID, COVID-T1, and COVID-T2.

Participants indicated their depressive symptoms using the 20-item Center for Epidemiologic Studies Depression Scale (CES-D; Radloff, 1977), rating symptoms of depressed affect, positive affect, somatic activity, and interpersonal relations on the frequency of symptoms experienced in the past week. Responses were indicated on a 4-point
Likert scale from $0=$ rarely or none of the time to $3=$ most or all of the time. Studies of the scale's psychometrics support its longitudinal invariance, that is, that changes in symptom scores on this scale reflect true symptom change (Ferro $\&$ Speechley, 2013). The alphas for the current study were $0.91,0.93$, and 0.93 respectively for pre-COVID, COVIDT1, and COVID-T2.

The COVID-19 surveys were conducted one month after stay-at-home and social distancing orders were put in place and again 6 months later, and included measures of COVID19 health risk, contextual hardship, coping, and appraisal, as well as maternal and child mental health.

COVID-19 Health Risk On the COVID-19 surveys, a measure of COVID-19 health risk was assessed. The cumulative index consisted of 9 factors. Dichotomous factors were getting a positive COVID-19 test, being instructed to quarantine, one's child having symptoms of COVID-19, being in close contact or living with an individual with COVID-19 symptoms, knowing someone who was hospitalized or died of COVID-19, and workplace exposure (COVID-T1 = working in a healthcare setting/hospital, COVID-T2 = any essential worker). Responses were scored $0=$ not present, $1=$ present. Continuous variables were health status $(0=$ very poor health to $4=$ very good health), medical engagement (a sum of consulting with a doctor, being hospitalized, and being tested for COVID-19), and COVID-19 symptoms (a sum of 9 common symptoms) that were converted into proportion scores. Component measures were largely based on constructs put forth by Wang and colleagues early in the COVID-19 pandemic (March 2020). These authors examined COVID-19 health and contact risks associated with mental health symptoms during the initial phase of the COVID-19 outbreak in China. Constructs were slightly tailored to apply the current sample.

COVID-19 Contextual Hardship On the COVID surveys, participants completed a measure of COVID-19 contextual hardship. The cumulative index consisted of 6 factors: lack of health insurance, employment loss, income decrease, childcare loss, housing insecurity, and household density. Three variables were scored dichotomously: Health insurance $(0=$ have insurance, $1=$ no insurance $)$, income $(0=$ more or same income as typical that month, $1=$ less income than typical that month $)$, and housing $(0=$ own, rent, or live with family, $1=$ temporary housing or homeless). The remaining continuous variables were converted into proportions of the total possible score. For employment, a reduction in hours was scored as 0.5 and not working, being furloughed, or laid off was scored as 1. For childcare changes, having reduced childcare was scored as 0.5 and having no childcare due to COVID-19 was scored as 1 . Household density was a proportion score of the number of people living 
in the home divided by 10. Similar to COVID-19 health risks, contextual hardships were based on factors identified by Wang and colleagues (2020) as relating to mental health symptoms, with tailoring to the current sample and timing of the study.

Coping On the COVID surveys, the Brief Coping Scale (BCS; Carver, 1997) was used to measure participants active and avoidant coping. Participants rated how much they employed a strategy to deal with a problem on a 4-point scale $(1=$ haven't been doing this at all to $4=\mathrm{I}$ 've been doing this a lot). The active coping subscale consisted of two items each addressing planning, positive reframing, acceptance, and active coping. The avoidant subscale consisted of two items each addressing self-distraction, denial, and behavioral disengagement. The BCS is an adapted version of the COPE Inventory (Carver et al., 1989) that has been validated in a post-disaster study (Carver, 1997). The alphas for the subscales were 0.88 and 0.69 respectively.

Threat Appraisal On the COVID questionnaires, threat appraisal was measured using the 15-item Post-traumatic Maladaptive Beliefs Scale (PMBS; Vogt et al., 2012). The measure was developed to assess maladaptive beliefs that may occur following trauma exposure while also addressing general beliefs with relevance for current life circumstances. Participants indicated how much a belief was true for them on a 7-point Likert-type response ranging from 1 (not at all true for you) to 7 (completely true for you). Threat appraisal was composed of three domains, each measured by five items: threat of harm, self-worth and judgment (reverse scored), and reliability and trustworthiness of others (reverse scored). The PMBS has been validated in post-disaster research (Vogt et al., 2012). The alpha for the current study was 0.90 .

Child Adjustment Problems Measures of child internalizing and externalizing problems were obtained at both the COVID-T1 and COVID-T2 assessments. Mothers of infants aged 16 months or older reported on symptoms using the Preschool Version of the Child Behavior Checklist (Achenbach $\&$ Rescorla, 2000). Mothers reported on their child's internalizing symptoms on 14-items capturing anxiety, depression, and somatic symptoms. Mothers reported on their children's externalizing symptoms on 10-items assessing attention problems, anger/defiance, and conduct problems. Responses noted the frequency of problem behaviors from 0 (not at all typical of the child) to 2 (often typical of the child). The alpha for the internalizing subscale was 0.80 and 0.82 at COVIDT1 and COVID-T2, respectively. The alpha for the externalizing subscale was 0.78 and 0.84 at COVID-T1 and COVID$\mathrm{T} 2$, respectively.

\section{Analytic Plan}

First, the means and standard deviations of the pre-COVID, COVID-T1, and COVID-T2 variables were examined. To provide descriptive information about how COVID-19-specific risks and mental health changed from before to during the pandemic, repeated measures ANOVAs were used to test for changes in mean levels across time.

Next, correlations were examined to identify potential covariates, and then analytic models were tested using structural equation modeling in Mplus (Muthén \& Muthén, 2010). FIML estimation was used to address missing data. To understand contributors to changes in maternal symptoms of anxiety and depression during the pandemic, preCOVID mental health symptoms and pre-COVID contextual risk as well as COVID-T1 contextual hardship, health risk, self-compassion, threat appraisal, active coping, and avoidant coping were specified as predictors of COVID-T1 mental health symptoms. Maternal mental health symptoms were a latent factor of symptoms of anxiety and depression.

Levels and changes in risk and maternal mental health during the pandemic were subsequently examined as predictors of levels and changes in child mental health, where child mental health was a latent factor of children's internalizing and externalizing symptoms. The model tested is depicted in Fig. 1. In these models, pre-COVID contextual risk and maternal mental health were examined as predictors of COVID-T1 contextual hardship, health risk, and maternal mental health, and these in turn were examined as predictors of COVID-T2 child adjustment. In addition, rank-order changes in contextual hardship, health risk, and maternal mental health from COVID-T1 to COVID-T2 were examined as predictors of rank-order changes in COVID-T1 to COVID-T2 child adjustment. This was done by specifying COVID-T1 levels of child adjustment on COVID-T2 variables as predictors of COVID-T2 child adjustment. Child age and sex were included as covariates. Finally, indirect effects of COVID-19 contextual hardship, COVID-19 health risk, and maternal mental health on COVID-T2 child adjustment problems were tested. These indirect effects evaluate if changes in maternal mental health accounted for the effects of COVID-19-specific risks on child adjustment and changes in child adjustment during the pandemic.

\section{Results}

\section{Missing Data}

Participants missing data on study variables on the COVID19 questionnaires $(n=27-31)$ were compared with those who completed the COVID-19 questionnaires on preCOVID variables to assess the extent of bias introduced by 


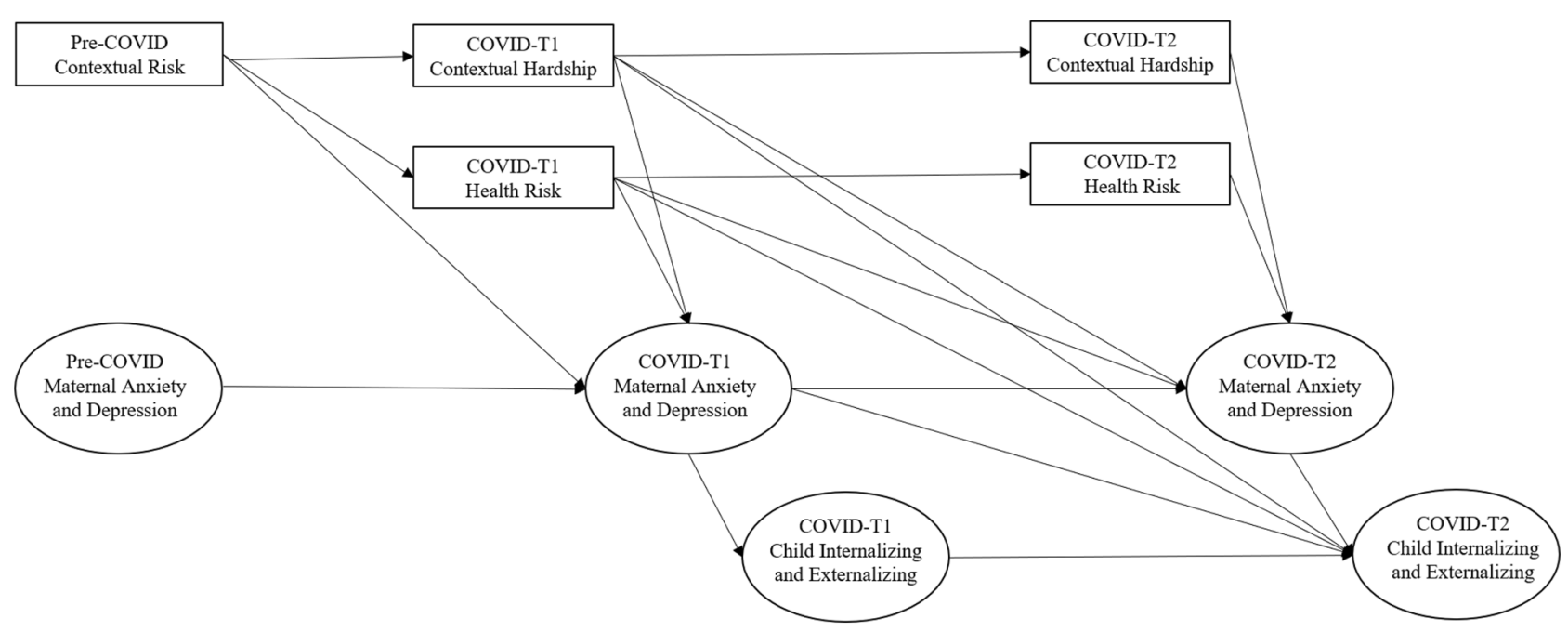

Fig. 1 Model testing effects of pre-COVID-19 contextual risk and maternal mental health on COVID-T1 levels of maternal mental health and child adjustment problems, and changes in COVID- 19-specific risk and maternal mental health from COVID-T1 to COVID-T2 on COVID-T2 levels of child adjustment

across-timepoint correlations between greater maternal mental health symptoms and greater child adjustment problems.

Means and standard deviations of the study variables from pre-pandemic, COVID-T1, and COVID-T2, along with tests of differences in means across time are presented in Table 3. Levels of maternal depression and anxiety increased significantly from pre-COVID-19 to COVID-T1. The levels declined somewhat by COVID-T2 but remained higher than pre-COVID-19 levels. COVID-19 health risk increased significantly from COVID-T1 to COVID-T2, whereas contextual hardship did not. Child internalizing and externalizing problems did not increase significantly on average from COVID-T1 to COVID-T2.

\section{Risk and Resilience Factors and Changes in Maternal Mental Health}

The overall path model examining the effects of COVID-19 specific predictors and maternal risk and resilience factors on changes in maternal mental health symptoms from prepandemic to COVID-T1 fit the data well $\left(\chi^{2}[35]=41.58\right.$, $p \geq 0.05, R M S E A=0.03, C F I=0.99)$. Standardized coefficients are reported in Table 4. Greater COVID-T1 contextual hardship and health risk predicted greater increases in maternal symptoms from pre-pandemic to COVID-T1. Higher threat appraisal predicted greater increases in symptoms from prepandemic to COVID-T1. Greater pre-existing self-compassion as well as reliance on active coping strategies predicted lower or less change in maternal mental health symptoms, whereas 


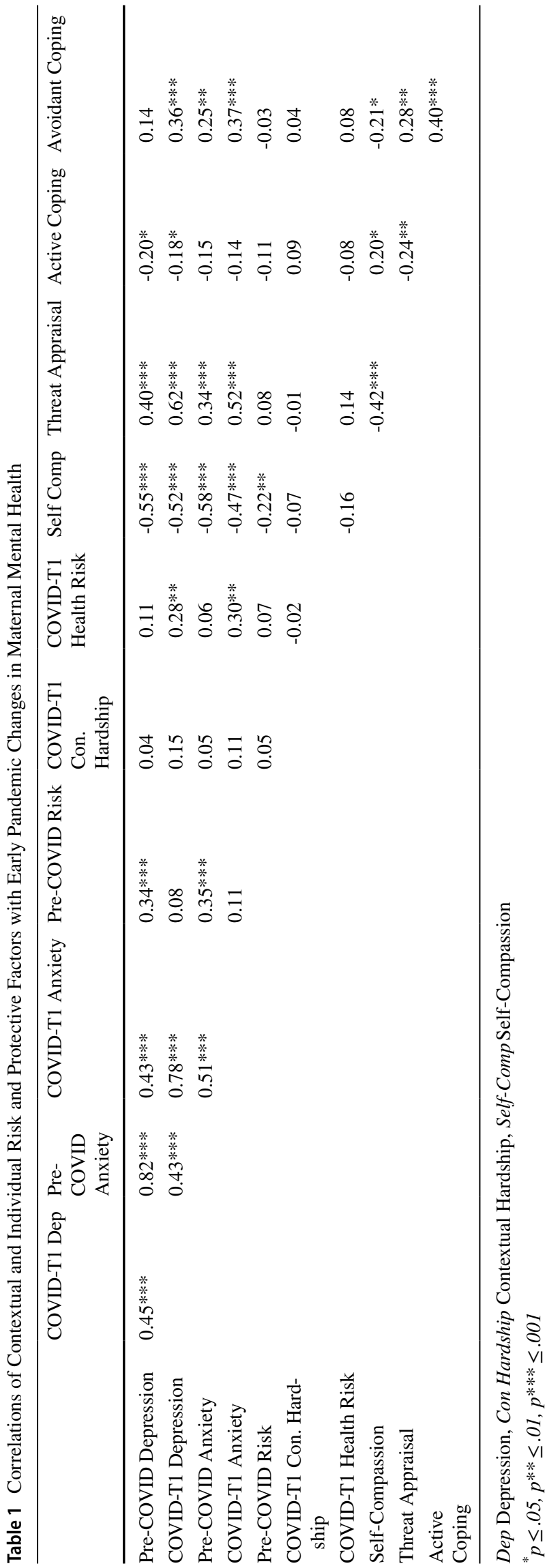

greater reliance on avoidant coping predicted greater increases in symptoms.

\section{Tests of Levels and Changes in Risk and Maternal Mental Health as Predictors of Changes in Child Adjustment}

Focusing on pre-COVID-19 and COVID-19-specific risk, we examined the extent to which changes in risk predicted changes in maternal mental health and child adjustment problems. The overall path model examining the effects of levels and rank-order changes in risk and maternal mental health as predictors of levels and changes in child adjustment is depicted in Fig. 1. Path model results are presented in Table 5. The model demonstrated adequate fit to the data $\left(\chi^{2}[39]=136.81\right.$, $p \geq 0.001, R M S E A=0.06, C F I=0.94)$. Children's levels of adjustment problems at COVID-T1 were predicted by higher maternal mental health symptoms. Maternal mental health symptoms were highly stable from COVID-T1 to COVID-T2, and none of the risk variables predicted rank-order changes in maternal mental health symptoms. Controlling for COVID-T1 levels of child adjustment problems, which were moderately stable from COVID-T1 to COVID-T2, concurrent COVID-T2 contextual hardship, which represented the residual or change from COVID-T1 levels, was related to smaller increases or decreases in children's adjustment problems. Change in COVID-19-specific health risk was related to smaller increases or decreases in children's internalizing symptoms. Concurrent COVID-T2 levels of maternal mental health symptoms, which represented the residual or change from COVID-T1 levels, were related to significant increases in children's adjustment problems.

\section{Tests of Indirect Effects of COVID-T1 Risk Factors on Child Adjustment Through Maternal Mental Health}

There was a significant indirect effect of COVID-T1 health risk on child adjustment through COVID-T1 and COVIDT2 maternal mental health symptoms $(\beta=0.17, S E=0.08$, $t=2.07, p=0.04$ ).

\section{Discussion}

Consistent with other studies, levels of maternal mental health symptoms increased significantly from before preCOVID to COVID-T1. Symptom levels declined somewhat by COVID-T2 but remained higher than prior to the pandemic. When testing predictors of changes in maternal mental health symptoms, pre-COVID-19 contextual risk was significantly related to levels of maternal mental health symptoms prior to COVID-19 but not to changes during 


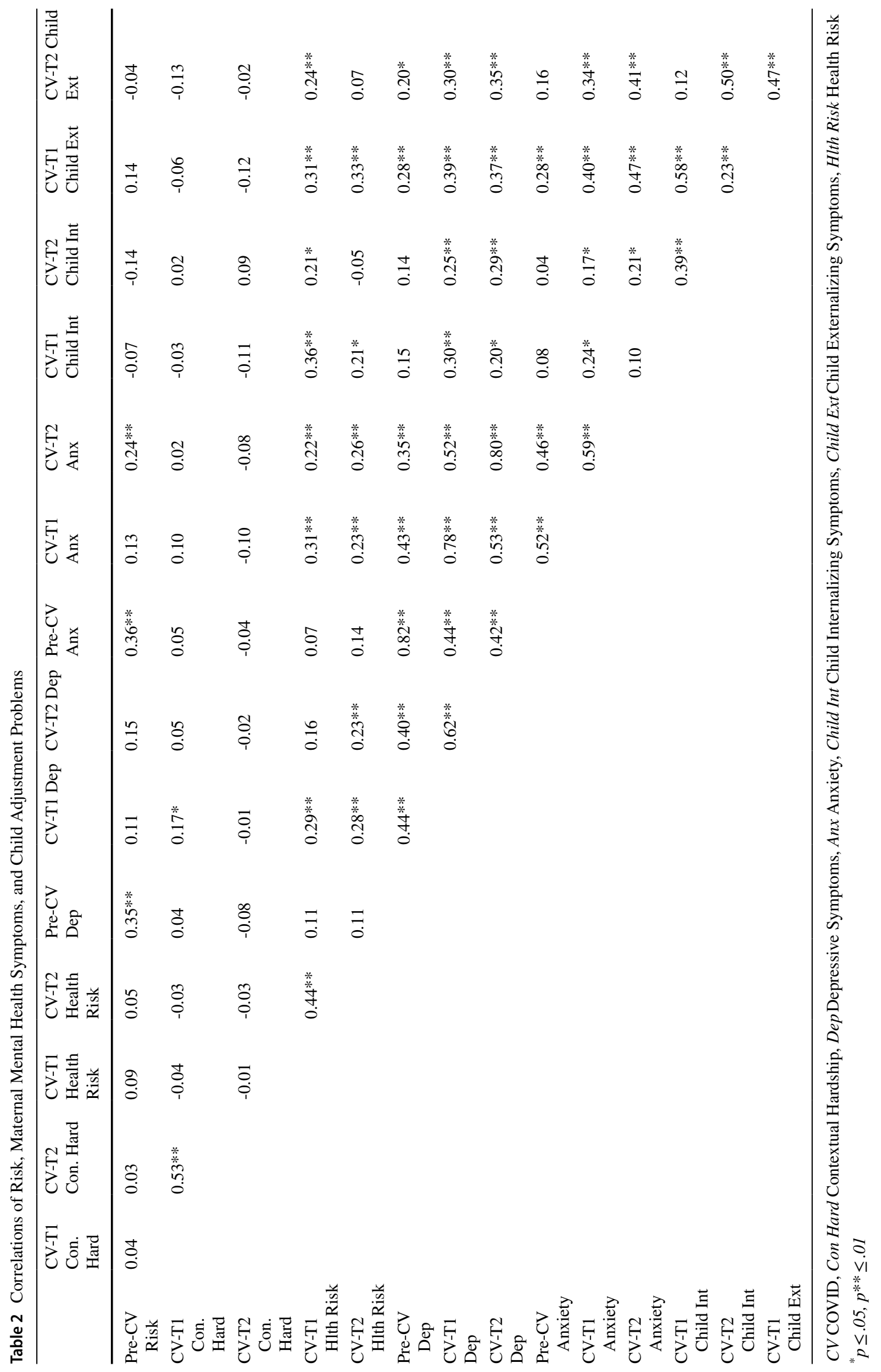


Table 3 Means, standard deviations pre-COVID, COVID-T1, COVID-T2 variables, and tests of mean differences

\begin{tabular}{|c|c|c|c|c|c|c|c|c|}
\hline & \multicolumn{2}{|c|}{ Pre-COVID-19 } & \multicolumn{2}{|c|}{ COVID-T1 } & \multicolumn{2}{|c|}{ COVID-T2 } & \multirow{2}{*}{$\begin{array}{l}\text { F }(\mathbf{d f}), \\
\text { p-value }\end{array}$} & \multirow{2}{*}{$\begin{array}{l}\text { C.I.s for } \\
\text { Differences }\end{array}$} \\
\hline & $\mathbf{M}$ & SD & $\mathbf{M}$ & SD & $\mathbf{M}$ & SD & & \\
\hline Pre-COVID Context Risk & 3.38 & 0.80 & - & - & - & - & - & \\
\hline Maternal Depression & 14.219 & 10.134 & 19.276 & 11.738 & 18.689 & 11.487 & $16.849(1,123),<.001$ & $\begin{array}{l}\text { a. } 2.943-7.171 \\
\text { b. } 2.315-6.626 \\
\text { c. }-1.319-2.492\end{array}$ \\
\hline Maternal Anxiety & 6.048 & 4.702 & 7.419 & 5.921 & 6.746 & 5.132 & $4.066(1,123), .018$ & $\begin{array}{l}\text { a. } 0.398-2.344 \\
\text { b. }-0.254-1.650 \\
\text { c. }-0.256-1.603\end{array}$ \\
\hline COVID-19 Health Risk & - & - & 1.789 & 1.349 & 2.207 & 1.520 & $8.787(1,134), .004$ & c. $0.139-0.698$ \\
\hline COVID-19 Con. Hardship & - & - & 1.820 & 0.915 & 1.944 & 0.824 & $2.211(1,127), .140$ & c. $-0.041-0.289$ \\
\hline Child Internalizing & - & - & 2.422 & 3.143 & 2.779 & 3.613 & $0.802(1,82), .373$ & c. $-0.436-1.151$ \\
\hline Child Externalizing & - & - & 5.440 & 4.030 & 5.545 & 3.257 & $0.057(1,82), .811$ & c. $-0.762-0.971$ \\
\hline
\end{tabular}

Confidence Intervals (C.I.s) for the differences between a) pre-COVID-19 and COVID-T1, b) pre-COVID-19 and COVID-T2, and c) COVID-T1 and COVID-T2

COVID-19. This suggests that the accumulation of sociodemographic risk factors was already taking a toll on maternal mental health prior to the pandemic in this low-income sample.

Individual resilience factors predicted changes in maternal mental health symptoms above the effects of risk. Preexisting self-compassion, or the non-judgmental understanding of one's pain and recognition of pain as part of a larger human experience, was associated with less change in symptoms of maternal mental health coinciding with the onset of the pandemic. This finding is consistent with the literature on self-compassion (MacBeth \& Gumley, 2012) though is unique in showing these relations in the context of a global health crisis.

COVID-19 contextual hardships predicted changes in maternal mental health symptoms and child adjustment. The contextual hardship variable captures changes

Table 4 Standardized Betas of Risk and Resilience Factors on Maternal Mental Health

\begin{tabular}{lll}
\hline & \multicolumn{2}{l}{$\begin{array}{l}\text { COVID-T1 Maternal } \\
\text { Mental Health }\end{array}$} \\
\cline { 2 - 3 } & $\beta$ & $\mathrm{SE}$ \\
\hline Pre-COVID-19 Predictors & & \\
Prior symptoms & $0.19^{*}$ & 0.09 \\
Pre-COVID-19 contextual risk & -0.07 & 0.08 \\
Self-compassion & $-0.17^{*}$ & 0.09 \\
COVID-19 Specific Predictors & & \\
COVID-T1 contextual hardship & $0.16^{* *}$ & 0.06 \\
COVID-T1 health risk & $0.21^{* * *}$ & 0.06 \\
Threat appraisal & $0.39^{* * *}$ & 0.07 \\
Active coping & $-0.14^{*}$ & 0.07 \\
Avoidant coping & $0.26^{* * *}$ & 0.08 \\
\hline
\end{tabular}

$* p \leq .05, p^{* *} \leq .01, p^{* * *} \leq .001$ to context such as employment and childcare losses. Consistent with Pakenham (2020), these disruptions to livelihood were found to register on adult mental health outcomes and further, to predict child adjustment as well. COVID-19 health risk predicted greater increases in maternal mental health symptoms, confirming that heightened exposure to the COVID-19 health risks played a meaningful role in mental health responses to the pandemic. Remarkably, pre-pandemic COVID-19 contextual risk was not related to these COVID-19specific risks, perhaps highlighting the uneven and inequitable distribution of COVID-19 supports, particularly along racial/ethnic lines (Gassman-Pines \& Gennetian, 2020).

Mothers' appraisal and coping during the pandemic additionally predicted changes in their mental health symptoms. Mothers' threat appraisal was associated with greater increases in symptoms, highlighting that beliefs of low agency, low trust in others, and internalization of the world as a dangerous place, while understandable in relation to disaster experiences, nevertheless are liabilities to mental health symptoms. Active and avoidant coping corresponded to changes in maternal mental health in predicted directions, with avoidant coping strategies, involving trying to stay away from the problem or repressing thoughts about problems, predicting greater increases in maternal mental health symptoms and more active, problem-solving coping predicting smaller increases or decreases in maternal mental health symptoms. This study finding suggests that while many aspects of the pandemic represent uncontrollable stress, avoiding thinking about or dealing with it tended to worsen adjustment to it, as is the typically observed relation of avoidant coping to maladjustment. The malleability of appraisal and coping (e.g., Moskowitz, 2011; Tomaka et al., 
Table 5 Standardized regression coefficients (standard errors) for the effects of pre-COVID-19 risk, COVID-19 risk and changes in COVID-19 risk in predicting levels and changes in maternal mental health symptoms and child adjustment problems

\begin{tabular}{|c|c|c|c|c|}
\hline & \multicolumn{2}{|c|}{ COVID-19 T1 (April 2020) } & \multicolumn{2}{|l|}{ COVID-19 T2 (October 2020) } \\
\hline & $\begin{array}{l}\text { Maternal Mental } \\
\text { Health }\end{array}$ & $\begin{array}{l}\text { Child } \\
\text { Adjustment Problems }\end{array}$ & $\begin{array}{l}\text { Maternal Mental } \\
\text { Health }\end{array}$ & $\begin{array}{l}\text { Child } \\
\text { Adjustment Problems }\end{array}$ \\
\hline \multicolumn{5}{|l|}{ Predictors } \\
\hline Child Age & $0.01(.08)$ & $-0.12(.14)$ & $-0.09(.07)$ & $-0.06(.11)$ \\
\hline Child Sex & $-0.01(.08)$ & $0.19(.10)^{\mathrm{t}}$ & $0.08(.08)$ & $-0.13(.10)$ \\
\hline \multicolumn{5}{|l|}{ Pre-COVID-19 } \\
\hline Contextual Risk & $-.07(.10)$ & $0.15(.11)$ & & \\
\hline $\begin{array}{l}\text { Pre-COVID Maternal } \\
\text { Mental Health }\end{array}$ & $0.57(.09) *$ & & & \\
\hline \multicolumn{5}{|l|}{ COVID-19 T1 } \\
\hline COVD-T1 Health Risk & $0.31(.07)^{*}$ & $0.21(.13)^{\mathrm{t}}$ & $-0.03(.09)$ & $0.23(.13)^{\mathrm{t}}$ \\
\hline $\begin{array}{l}\text { COVD-T1 Contextual } \\
\text { Hardship }\end{array}$ & $0.13(.09)$ & $-0.14(.10)$ & $-0.06(.09)$ & $-0.26(.12)^{*}$ \\
\hline $\begin{array}{l}\text { COVD-T1 Maternal } \\
\text { Mental Health }\end{array}$ & & $0.38(.11)^{*}$ & $0.67(.07)^{*}$ & $0.20(.17)$ \\
\hline $\begin{array}{l}\text { COVD-T1 Child } \\
\text { Adjustment } \\
\text { Problems }\end{array}$ & & & & $0.07(.19)$ \\
\hline \multicolumn{5}{|l|}{ COVID-19 T2 } \\
\hline $\begin{array}{l}\text { COVID-T2 Health } \\
\text { Risk }\end{array}$ & & & $0.12(.08)$ & $-0.24(.11)^{*}$ \\
\hline $\begin{array}{l}\text { COVID-T2 Contextual } \\
\text { Hardship }\end{array}$ & & & $-0.04(.09)$ & $0.20(.11)^{\mathrm{t}}$ \\
\hline $\begin{array}{l}\text { COVID-T2 Maternal } \\
\text { Mental Health }\end{array}$ & & & & $0.37(.17)^{*}$ \\
\hline
\end{tabular}

${ }^{\mathrm{t}} \leq .10, * p \leq .05$

1993) and the promotive effects of active coping make these cognitive processes potentially fruitful targets for interventions aimed at ameliorating the negative effects of the pandemic or other disasters on maternal mental health.

Given the known association between parental and offspring mental health, as well as the research that children face worse mental health outcomes in the aftermath of a disaster if their caregiver's mental health has declined, the current study examined whether levels of and changes in maternal mental health predicted changes in young children's adjustment. At COVID-T1, maternal mental health symptoms predicted higher concurrent child adjustment problems. At COVID-T2, changes in toddlers' adjustment problems were predicted by early pandemic levels of COVID-19 contextual hardship, as well as change in COVID-specific health risk and changes in maternal mental health. COVID19 health risk predicted less change in child adjustment, with greater exposure to health risk relating to higher levels of child adjustment problems that remained high across the pandemic. Greater increases in maternal mental health symptoms predicted increases in child adjustment problems, highlighting the close interconnection between parent and offspring mental health.
Finally, this study tested whether changes in maternal mental health served as a pathway for the effects of COVID19-specific risk on child adjustment. There was a significant indirect effect of COVID-19 health risk on children's adjustment problems through COVID-T1 and then COVIDT2 maternal mental health symptoms. This finding affirms the centrality of parental mental health in serving as the mechanism by which adversity influences child adjustment (e.g., Family Stress Model; Masarik \& Conger, 2017), and as a central consequence of the pandemic, with cascading implications for families (Masten, 2021).

The findings of the current study should be interpreted in the context of its limitations. This study examined the experiences of a sample of mothers with young children living in low income contexts, a sample that is likely to be at particularly high risk of mental health challenges the during COVID-19 pandemic. Although it is important to examine these experiences of risk, the nature of the sample might result in a restricted range of risk experiences relative to a wider income range and affect generalizability of findings. Further, we did not assess a broader set of resilience factor prior to the pandemic, and as a result, some of the resilience factors examined (appraisal and coping) were 
assessed concurrently with COVID-T1 mental health. As such, reports on these measures might have been biased by mothers' mental health status.

The current study did not include numerous factors deserving further study. Parenting behaviors, which the current study does not include, are a critical mechanism in Family Stress Models and have been shown to mediate the effects of maternal mental health on child psychosocial adjustment in the context of severe hardship (Sim et al., 2018). Additionally, this study did not consider the role of second caregivers in understanding maternal and child adjustment during the COVID-19 pandemic. Given the research that indicates that both mothers and fathers may be experiencing mental health symptoms during the COVID-19 pandemic (Patrick et al., 2020), the delineated pathway from pandemic-related economic uncertainty to symptoms of depression in fathers to their paternal caregiving (Cito et al., 2020), the link between paternal and child mental health symptoms (Weitzman et al., 2011; Yogman et al., 2016), and conversely, the potential for a second parent's involvement or well-being to mitigate the effects of maternal mental health symptoms (Kahn et al., 2004), second caregivers represent an important direction for future research. Finally, further studies could extend the current work through the inclusion of broader social, neighborhood, and community factors.

Contributions of this study include the availability of prepandemic measures of mental health, which allow for the examination of changes to mental health coinciding with the start of the pandemic. Additionally, the current study considers cumulative risk indexes spanning domains of pre-pandemic contextual risk, COVID-19 contextual hardships and health risks, offering a comprehensive, though not exhaustive, characterization of the role of ecology in mental health. In addition to considering sources of risk, the current study answers the call for consideration of resilience factors that can be promotive in the context of crisis (Holmes et al., 2020a, b). This study utilized a diverse sample of families living in the context of low income who are likely experiencing undue and lasting burdens of the pandemic to illustrate the close linkage between changes in maternal mental health and children's adjustment.

Recent discourse on the pandemic has highlighted its multisystemic nature, with disruptions evident on the lives of children and families, as well as communities, economies, and societies (Masten \& Motti-Stefanidi, 2020). While the current study highlights potential cascades of risk experienced by mothers living in low-income contexts, it also highlights multiple avenues for the promotion of resilience, specifically through avenues including self-compassion and adaptive coping. Timely and effective interventions will be essential to repairing parents' mental well-being before effects are more enduring and detrimental to children's mental health.
Authors' Contribution All authors contributed to the study conception and design. Material preparation, data collection and analysis were performed by Stephanie F. Thompson, Lisa Shimomaeda, Rebecca Calhoun, Natasha Moini, \& Liliana J. Lengua. The first draft of the manuscript was written by Stephanie F. Thompson and all authors commented on previous versions of the manuscript. All authors read and approved the final manuscript.

Funding Support for this research was provided by a gift from the Maritz Family Foundation and by the University of Washington Population Health Initiative Pilot Research Grants both awarded to the last author.

\section{Compliance with Ethical Standards}

Ethics Approval This study was performed in line with the principles of the Declaration of Helsinki. Approval was granted by the Institutional Review Board at the University of Washington (1/11/2017, STUDY00000865).

Informed Consent Informed consent was obtained from all individual participants included in the study.

Code and Data Transparency The datasets generated during and/or analyzed during the current study and corresponding code are available from the corresponding author on reasonable request.

Conflicts of Interest The authors have no relevant financial or nonfinancial interests to disclose.

\section{References}

Achenbach, T. M., \& Rescorla, L. (2000). Manual for the ASEBA Preschool Forms and Profiles. University of Vermont, Research Center for Children, Youth, and Families.

Bonanno, G. A., Brewin, C. R., Kaniasty, K., \& Greca, A. M. L. (2010). Weighing the costs of disaster: Consequences, risks, and resilience in individuals, families, and communities. Psychological Science in the Public Interest, 11(1), 1-49. https://doi.org/10. 1177/1529100610387086

Brooks, S. K., Webster, R. K., Smith, L. E., Woodland, L., Wessely, S., Greenberg, N., et al. (2020). The psychological impact of quarantine and how to reduce it: Rapid review of the evidence. The Lancet, 395(10227), 912-920.

Cameron, E. E., Joyce, K. M., Delaquis, C. P., Reynolds, K., Protudjer, J. L. P., \& Roos, L. E. (2020). Maternal psychological distress $\&$ mental health service use during the COVID-19 pandemic. Journal of Affective Disorders, 276, 765-774. https://doi.org/10. 1016/j.jad.2020.07.081

Carver, C. S. (1997). You want to measure coping but your protocol' too long: Consider the brief cope. International Journal of Behavioral Medicine, 4(1), 92. https://doi.org/10.1207/ s15327558ijbm0401_6

Carver, C. S., Weintraub, J. K., \& Scheier, M. F. (1989). Assessing Coping Strategies: A Theoretically Based Approach. Journal of Personality and Social Psychology, 56, 267-283.

CDC. (2020, March 28). COVID Data Tracker. Centers for Disease Control and Prevention. https://covid.cdc.gov/covid-data-tracker

Cito, G., Micelli, E., Cocci, A., Polloni, G., Coccia, M. E., Carini, M., Minervini, A., \& Natali, A. (2020). Paternal behaviors in the era of COVID-19. The World Journal of Men's Health, 38(3), 251-253. https://doi.org/10.5534/wjmh.200071 
Compas, B. E., Connor-Smith, J. K., Saltzman, H., Thomsen, A. H., \& Wadsworth, M. E. (2001). Coping with stress during childhood and adolescence: Problems, progress, and potential in theory and research. Psychological Bulletin, 127(1), 87-127. https://doi.org/ 10.1037/0033-2909.127.1.87

Eamon, M. K., \& Zuehl, R. M. (2001). Maternal depression and physical punishment as mediators of the effect of poverty on socioemotional problems of children in single-mother families. American Journal of Orthopsychiatry, 71(2), 218-226. https://doi.org/10. 1037/0002-9432.71.2.218

Evans, G. W., \& Cassells, R. C. (2014). Childhood poverty, cumulative risk exposure, and mental health in emerging adults. Clinical Psychological Science, 2(3), 287-296. https://doi.org/10.1177/ 2167702613501496

Evans, G. W., Li, D., \& Whipple, S. S. (2013). Cumulative risk and child development. Psychological Bulletin, 139(6), 1342-1396. https://doi.org/10.1037/a0031808

Ferro, M. A., \& Speechley, K. N. (2013). Factor structure and longitudinal invariance of the Center for Epidemiological Studies Depression Scale (CES-D) in adult women: Application in a population-based sample of mothers of children with epilepsy. Archives of Women's Mental Health, 16(2), 159-166. https://doi. org/10.1007/s00737-013-0331-5

Fortuna, L. R., Tolou-Shams, M., Robles-Ramamurthy, B., \& Porche, M. V. (2020). Inequity and the disproportionate impact of COVID-19 on communities of color in the United States: The need for a trauma-informed social justice response. Psychological Trauma: Theory, Research, Practice, and Policy, 12(5), 443. https://doi.org/10.1037/tra0000889

Gassman-Pines, A., Ananat, E. O., \& Fitz-Henley, J. (2020). COVID19 and parent-child psychological well-being. Pediatrics, 146(4), e2020007294. https://doi.org/10.1542/peds.2020-007294

Gassman-Pines, A., \& Gennetian, L. A. (2020). COVID-19 job and income loss jeopardize child well-being: Income support policies can help (No. 9; SRCD Child Evidence Brief). Society for Research on Child Development. https://www.srcd.org/ research/covid-19-job-and-income-loss-jeopardize-childwell-being-income-support-policies-can-help. Accessed Date 24 November 2020.

Goodman, S. H., Rouse, M. H., Connell, A. M., Broth, M. R., Hall, C. M., \& Heyward, D. (2011). Maternal depression and child psychopathology: A meta-analytic review. Clinical Child and Family Psychology Review, 14(1), 1-27. https://doi.org/10.1007/ s10567-010-0080-1

Hayes, J. A., Lockard, A. J., Janis, R. A., \& Locke, B. D. (2016). Construct validity of the Self-Compassion Scale-Short Form among psychotherapy clients. Counselling Psychology Quarterly, 29(4), 405-422. https://doi.org/10.1080/09515070.2016.1138397

Holmes, E. A., O'Connor, R. C., Perry, V. H., Tracey, I., Wessely, S., Arseneault, L., Ballard, C., Christensen, H., Cohen Silver, R., Everall, I., Ford, T., John, A., Kabir, T., King, K., Madan, I., Michie, S., Przybylski, A. K., Shafran, R., Sweeney, A., \& Bullmore, E. (2020). Multidisciplinary research priorities for the COVID-19 pandemic: A call for action for mental health science. The Lancet Psychiatry, 7(6), 547-560. https://doi.org/10.1016/ S2215-0366(20)30168-1

Holmes, L., Enwere, M., Williams, J., Ogundele, B., Chavan, P., Piccoli, T., Chinaka, C., Comeaux, C., Pelaez, L., Okundaye, O., Stalnaker, L., Kalle, F., Deepika, K., Philipcien, G., Poleon, M., Ogungbade, G., Elmi, H., John, V., \& Dabney, K. W. (2020). Black-White risk differentials in COVID-19 (SARSCOV2) transmission, mortality and case fatality in the United States: Translational epidemiologic perspective and challenges. International Journal of Environmental Research and Public Health, 17(12), 4322. https://doi.org/10.3390/ijerph17124322
Jenkins, E. K., McAuliffe, C., Hirani, S., Richardson, C., Thomson, K. C., McGuinness, L., Morris, J., Kousoulis, A., \& Gadermann, A. (2021). A portrait of the early and differential mental health impacts of the COVID-19 pandemic in Canada: Findings from the first wave of a nationally representative cross-sectional survey. Preventive Medicine, 145, 106333. https://doi.org/10.1016/j. ypmed.2020.106333

Kahn, R. S., Brandt, D., \& Whitaker, R. C. (2004). Combined effect of mothers' and fathers' mental health symptoms on children's behavioral and emotional well-being. Archives of Pediatrics \& Adolescent Medicine, 158, 721-729.

Kelly, A. C., Carter, J. C., Zuroff, D. C., \& Borairi, S. (2013). Selfcompassion and fear of self-compassion interact to predict response to eating disorders treatment: A preliminary investigation. Psychotherapy Research, 23(3), 252-264. https://doi.org/10. 1080/10503307.2012.717310

King County. (2020). COVID-19 outbreak summary dashboard. King County. https://kingcounty.gov/depts/health/covid-19/data/dailysummary.aspx

Lazarus, R., \& Folkman, S. (1984). Stress, Appraisal, and Coping. Springer Publishing Company.

Lea, C. S., Littleton, H., Allen, A. B., \& Beasley, C. M. (2020). Resilience, Self-compassion, and Mental Health Outcomes: Rebuilding Eastern North Carolina After Natural Disasters. North Carolina Medical Journal, 81(5), 315-319. https://doi.org/10.18043/ncm. 81.5.315

Löwe, B., Decker, O., Müller, S., Brähler, E., Schellberg, D., Herzog, W., \& Herzberg, P. Y. (2008). Validation and standardization of the Generalized Anxiety Disorder Screener (GAD-7) in the general population. Medical Care, 46(3), 266-274.

Lyons-Ruth, K., Wolfe, R., Lyubchik, A., \& Steingard, R. (2002). Depressive symptoms in parents of children under age 3: Sociodemographic predictors, current correlates, and associated parenting behaviors. In N. Halfon, K. T. McLarn, \& M. A. Schuster (Eds.), Child rearing in America: Challenges facing parents with young children (pp. 217-259). Cambridge University Press.

MacBeth, A., \& Gumley, A. (2012). Exploring compassion: A metaanalysis of the association between self-compassion and psychopathology. Clinical Psychology Review, 32(6), 545-552. https:// doi.org/10.1016/j.cpr.2012.06.003

Mars, B., Collishaw, S., Smith, D., Thapar, A., Potter, R., Sellers, R., Harold, G. T., Craddock, N., Rice, F., \& Thapar, A. (2012). Offspring of parents with recurrent depression: Which features of parent depression index risk for offspring psychopathology? Journal of Affective Disorders, 136(1-2), 44-53. https://doi.org/ 10.1016/j.jad.2011.09.002

Masarik, A. S., \& Conger, R. D. (2017). Stress and child development: A review of the Family Stress Model. Current Opinion in Psychology, 13, 85-90. https://doi.org/10.1016/j.copsyc.2016.05.008

Masten, A. S. (2021). Resilience of children in disasters: A multisystem perspective. International Journal of Psychology, 56(1), 1-11. https://doi.org/10.1002/ijop.12737

Masten, A. S., \& Motti-Stefanidi, F. (2020). Multisystem Resilience for Children and Youth in Disaster: Reflections in the Context of COVID-19. Adversity and Resilience Science, 1(2), 95-106. https://doi.org/10.1007/s42844-020-00010-w

Masten, A. S., \& Narayan, A. J. (2012). Child development in the context of disaster, war, and terrorism: Pathways of risk and resilience. Annual Review of Psychology, 63, 227-257.

Moskowitz, J. T. (2011). Coping interventions and the regulation of positive affect. In The Oxford handbook of stress, health, and coping (pp. 407-427). Oxford University Press.

Muthén, L. K., \& Muthén, B. O. (2010). Mplus User's Guide, Sixth Edition. Múthen \& Múthen.

Pakenham, K. I., Landi, G., Boccolini, G., Furlani, A., Grandi, S., \& Tossani, E. (2020). The moderating roles of psychological 
flexibility and inflexibility on the mental health impacts of COVID19 pandemic and lockdown in Italy. Journal of Contextual Behavioral Science, 17, 109-118. https://doi.org/10.1016/j.jcbs.2020. 07.003

Panting, A., Heise, A. G., Hechanova, Ma. R. M., \& Waelde, L. C. (2020). Mindfulness Interventions for Disaster Resilience in Southeast Asia. In Ma. R. M. Hechanova \& L. C. Waelde (Eds.), Community, Environment and Disaster Risk Management (pp. 95-108). Emerald Publishing Limited. https://doi.org/10.1108/ S2040-726220200000021006

Park, C. L., Finkelstein-Fox, L., Russell, B. S., Fendrich, M., Hutchison, M., \& Becker, J. (2021). Americans' distress early in the COVID-19 pandemic: Protective resources and coping strategies. Psychological Trauma: Theory, Research, Practice, and Policy. https://doi.org/10.1037/tra0000931

Patrick, S. W., Henkhaus, L. E., Zickafoose, J. S., Lovell, K., Halvorson, A., Loch, S., Letterie, M., \& Davis, M. M. (2020). Well-being of parents and children during the COVID-19 pandemic: A national survey. Pediatrics, 146(4), e2020016824. https://doi.org/10.1542/ peds.2020-016824

Penkler, M., Müller, R., Kenney, M., \& Hanson, M. (2020). Back to normal? Building community resilience after COVID-19. The Lancet Diabetes \& Endocrinology, 8(8), 664-665. https://doi. org/10.1016/S2213-8587(20)30237-0

Pierce, M., Hope, H., Ford, T., Hatch, S., Hotopf, M., John, A., Kontopantelis, E., Webb, R., Wessely, S., McManus, S., \& Abel, K. M. (2020). Mental health before and during the COVID-19 pandemic: A longitudinal probability sample survey of the UK population. The Lancet Psychiatry, 7(10), 883-892. https://doi.org/10.1016/S2215-0366(20)30308-4

Piotrkowski, C. S., \& Brannen, S. J. (2002). Exposure, threat appraisal, and lost confidence as predictors of PTSD symptoms following September 11, 2001. American Journal of Orthopsychiatry, 72(4), 476-485. https://doi.org/10.1037/0002-9432.72.4.476

Prime, H., Wade, M., \& Browne, D. T. (2020). Risk and resilience in family well-being during the COVID-19 pandemic. American Psychologist, 75(5), 631-643. https://doi.org/10.1037/ amp0000660

Radloff, L. S. (1977). The CES-D scale: A self-report depression scale for research in the general population. Applied Psychological Measurement, 1(3), 385-401.

Raes, F., Pommier, E., Neff, K. D., \& Van Gucht, D. (2011). Construction and factorial validation of a short form of the SelfCompassion Scale. Clinical Psychology \& Psychotherapy, 18(3), 250-255. https://doi.org/10.1002/cpp.702

Russell, B. S., Hutchison, M., Tambling, R., Tomkunas, A. J., \& Horton, A. L. (2020). Initial Challenges of Caregiving During COVID-19: Caregiver Burden, Mental Health, and the ParentChild Relationship. Child Psychiatry \& Human Development, 51(5), 671-682. https://doi.org/10.1007/s10578-020-01037-x

Sim, A., Bowes, L., \& Gardner, F. (2018). Modeling the effects of war exposure and daily stressors on maternal mental health, parenting, and child psychosocial adjustment: A cross-sectional study with Syrian refugees in Lebanon. Global Mental Health, 5, e40. https:// doi.org/10.1017/gmh.2018.33

Spitzer, R. L., Kroenke, K., Williams, J. B. W., \& Löwe, B. (2006). A brief measure for assessing Generalized Anxiety Disorder: The GAD-7. Archives of Internal Medicine, 166(10), 1092-1097. https://doi.org/10.1001/archinte.166.10.1092

Stein, A., Malmberg, L.-E., Sylva, K., Barnes, J., \& Leach, P. (2008). The influence of maternal depression, caregiving, and socioeconomic status in the post-natal year on children's language development. Child: Care, Health and Development, 34(5), 603-612. https://doi.org/10.1111/j.1365-2214.2008.00837.x

Stein, A., Pearson, R. M., Goodman, S. H., Rapa, E., Rahman, A., McCallum, M., Howard, L. M., \& Pariante, C. M. (2014). Effects of perinatal mental disorders on the fetus and child. The Lancet, 384(9956), 1800-1819. https://doi.org/10.1016/S0140-6736(14) $61277-0$

Tabachnick, B. G., \& Fidell, L. S. (2011). Multivariate Analysis of Variance (MANOVA). In M. Lovric (Ed.), International Encyclopedia of Statistical Science (pp. 902-904). Springer. https:// doi.org/10.1007/978-3-642-04898-2

Tomaka, J., Blascovich, J., Kelsey, R. M., \& Leitten, C. L. (1993). Subjective, physiological, and behavioral effects of threat and challenge appraisal. Journal of Personality and Social Psychology, 65(2), 248-260. https://doi.org/10.1037/0022-3514.65.2.248

Vogt, D. S., Shipherd, J. C., \& Resick, P. A. (2012). Posttraumatic Maladaptive Beliefs Scale: Evolution of the Personal Beliefs and Reactions Scale. Assessment, 19(3), 308-317. https://doi.org/10. 1177/1073191110376161

Wadsworth, M. E. (2015). Development of maladaptive coping: A functional adaptation to chronic, uncontrollable Stress. Child Development Perspectives, 9(2), 96-100. https://doi.org/10.1111/ cdep. 12112

Wang, C., Pan, R., Wan, X., Tan, Y., Xu, L., Ho, C. S., \& Ho, R. C. (2020). Immediate psychological responses and associated factors during the initial stage of the 2019 Coronavirus disease (COVID19) epidemic among the general population in China. International Journal of Environmental Research and Public Health, 17(5), 1729. https://doi.org/10.3390/ijerph17051729

Weitzman, M., Rosenthal, D. G., \& Liu, Y.-H. (2011). Paternal depressive symptoms and child behavioral or emotional problems in the United States. Pediatrics, 128(6), 1126-1134. https://doi.org/10. 1542/peds.2010-3034

Yogman, M., Garfield, C. F., \& COMMITTEE ON PSYCHOSOCIAL ASPECTS OF CHILD AND FAMILY HEALTH. (2016). Fathers roles in the care and development of their children: The role of pediatricians. Pediatrics, 138(1), e20161128-e20161128. https:// doi.org/10.1542/peds.2016-1128.

Publisher's Note Springer Nature remains neutral with regard to jurisdictional claims in published maps and institutional affiliations. 